\section{Commentary: Coronavirus disease 2019 (COVID-19) and the airway: How can surgery help?}

\author{
Erino Angelo Rendina, MD, and Giulio Maurizi, MD
}

We have read with interest the paper from Lucchi and colleagues ${ }^{1}$ reporting on one case of laryngotracheal resection for benign stenosis in a patient post-coronavirus disease 2019 (COVID-19); this is certainly one of the first reports in this setting. The Pisa University team has done a very good job in such a demanding condition. Moreover, this paper offers the opportunity to learn more about COVID-19 and related airway diseases; also, it gives us important insights about the role of surgery in this setting.

The first interesting aspect is that what the authors have described might be more and more frequent over the next months or years. In fact, a large number of cases of benign tracheal stenosis is eventually expected because of the prolonged intubation and/or tracheostomy performed to manage the severe respiratory impairment occurring in many patients with COVID-19. The authors reported the presence of a process of coagulative necrosis in the tissue of the resected airway (documented at the pathologic examination), thus confirming the recently published literature that points out the systemic effect of the COVID-19 that sometimes leads to multiorgan involvement. Interestingly, the authors did not report any additional technical difficulty related to this specific condition compared with a laryngotracheal reconstruction performed in a standard situation. ${ }^{2}$ Conversely, we experienced very hard and peculiar inflammatory tissues that persisted in the peritracheal area during the dissection and the following airway reconstruction when we recently performed tracheal reconstruction with

\footnotetext{
From the Division of Thoracic Surgery, Sant'Andrea Hospital, Sapienza University of Rome, Rome, Italy.

Disclosures: The authors reported no conflicts of interest.

The Journal policy requires editors and reviewers to disclose conflicts of interest and to decline handling or reviewing manuscripts for which they may have a conflict of interest. The editors and reviewers of this article have no conflicts of interest.

Received for publication Sept 11, 2020; revisions received Sept 11, 2020; accepted for publication Sept 24, 2020; available ahead of print Sept 28, 2020.

Address for reprints: Giulio Maurizi, MD, Division of Thoracic Surgery, "Sapienza" University of Rome - "Sant'Andrea" Hospital, Via di Grottarossa, 1035, 00189

Rome, Italy (E-mail: giuliomaurizi@libero.it).

JTCVS Techniques 2020;4:365

2666-2507

Copyright (C) 2020 The Authors. Published by Elsevier Inc. on behalf of The American Association for Thoracic Surgery. This is an open access article under the CC BY-NCND license (http://creativecommons.org/licenses/by-nc-nd/4.0/).

https://doi.org/10.1016/j.xjtc.2020.09.026
}

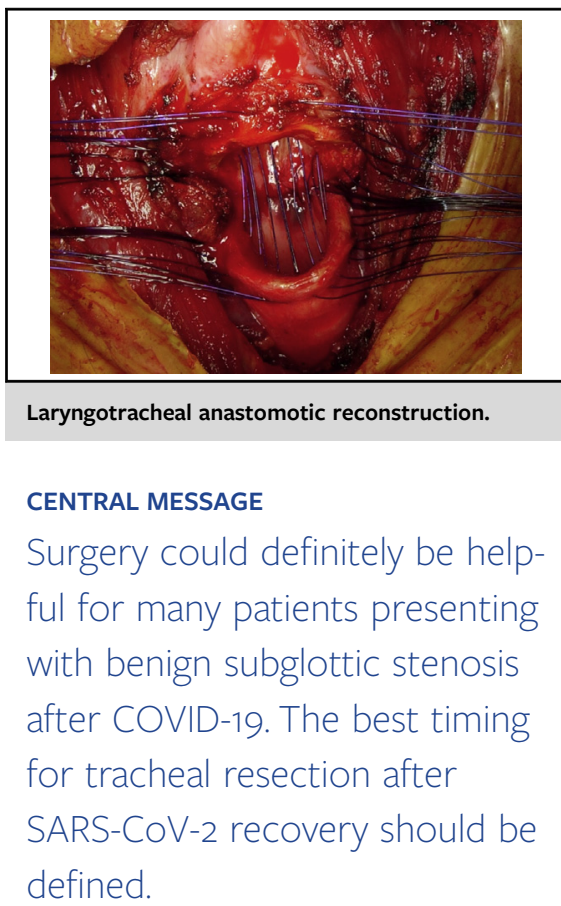

success in 4 patients who just recovered from severe acute respiratory syndrome coronavirus 2 (SARS-CoV-2; postintubation stenosis in 2 cases and tracheoesophageal fistula in other 2 cases). These operations were all extremely technically demanding. Based on this limited experience, we cannot provide conclusive recommendations. Nevertheless, we are convinced that a study should be conducted to better investigate and define the best timing for tracheal resection after SARS-CoV-2 recovery. There is no doubt that we are facing a new disease causing an entirely new set of disorders that must still be fully understood. COVID-19 will probably be a problem for a long time. Surgery could definitely be helpful for many patients post-COVID-19, but at the right time and with a very careful or cautious approach. An unpredictable scenario has happened, and we have no other choice than learn with experience to further define how surgery can be helpful in patients who have or had SARS-CoV-2.

We thank all the women and men of our institution who tirelessly make patient care possible every day, even at this difficult COVID-19 pandemic time.

\section{References}

1. Lucchi M, Ambrogi M, Aprile V, Ribechini A, Fontanini G. Laryngotracheal resection for a post-tracheotomy stenosis in a patient with coronavirus disease 2019 (COVID-19). J Thorac Cardiovasc Surg Tech. 2020;4:360-4.

2. D'Andrilli A, Maurizi G, Andreetti C, Ciccone AM, Ibrahim M, Poggi C, et al Long term results of laryngo-tracheal resection for benign stenosis from a series of 109 consecutive patients. Eur J Cardiothorac Surg. 2016;50:105-9. 